\title{
VADRINE COMBINED WITH SULPHONE IN THE TREATMENT OF LEPROMATOUS LEPROSY
}

\author{
By W. H. Jopling, M.R.C.P., D.T.M.\&H. \\ and D. S. RIDLEY, M.D., B.SC. \\ The Jordan Hospital, Earlswood, Surrey, and \\ Hospital for Tropical Diseases, London
}

Vadrine (the p-aminosalicylate of 2-pyridyl-(4)-1, 3, 4,-oxydiazolone-(5) ) was found to possess appreciable activity in lepromatous leprosy in a small trial of 7 patients (Jopling and Ridley, 1958), but the subsequent development of drug resistance in the majority after 9-15 months' treatment discouraged us from carrying out further trials of the compound used alone. However, because of the very promising initial response in some of these patients, and the complete absence of toxic effects, we decided to give Vadrine a trial in combination with sulphone.

\section{Method}

Five lepromatous patients admitted consecutively to the Jordan Hospital (2 European, 1 West Indian, 1 Nigerian, 1 Indian) received Vadrine together with standard doses of sulphone. They had not been treated previously. In the hope of minimising the chances of Vadrine-resistant strains of bacilli emerging, the dosage was increased more rapidly than in the previous trial, as follows:

1st week: One tablet of $200 \mathrm{mg}$. twice daily (400mg./day).

2nd week: Two tablets of $200 \mathrm{mg}$. twice daily (800mg./day).

3rd week: Three tablets of $200 \mathrm{mg}$. twice daily (1200mg./day).

4th week: Four tablets of $200 \mathrm{mg}$. twice daily (1600mg./day).

Dosage was not increased further once it reached $40 \mathrm{mg} . / \mathrm{kg} . / \mathrm{day}$, i.e. $2000 \mathrm{mg}$./day for a $50 \mathrm{~kg}$. patient. On the larger dosage we were able to use $500 \mathrm{mg}$. tablets instead of $200 \mathrm{mg}$.

Clinical progress was observed and recorded at weekly intervals, photographs were taken before treatment and subsequently every 6 months, and bacteriological progress was assessed by carrying out 6-8 skin smears and 2 skin biopsies every 6 months.

The small number of new admissions did not permit the concurrent treatment of control cases on sulphone alone, and it was therefore necessary to evaluate the progress of our 5 patients against our well documented records of previously admitted similar lepromatous patients who had received sulphone therapy. 


\section{Clinical results}

During the first 6 months all 5 patients made excellent clinical improvement, and by the end of this period all macules had disappeared and the majority of plaques and nodules had become flattened and impalpable. The rate of improvement appeared to be more rapid than that which could have been expected from sulphone alone; in fact, the improvement after 6 months was comparable with that which we would have expected after 12 months' treatment with sulphone alone. During the course of the next 6 months the remaining skin lesions disappeared leaving no trace apart from pigmentation in some instances, but the paucity and smallness of the remaining lesions at this stage made it difficult to compare subsequent progress with that which would have been expected from sulphone alone.

Erythema nodosum leprosum (ENL) developed in 3 patients during the first year causing serious interruption of treatment from the beginning of the second 6 months in Case 3 (see below) and during the second year in Cases 4 and 5, thus making further evaluation of therapy impossible.

\section{Bacteriological results}

As in the earlier trial, combined bacteriological and histological progress was assessed on an index obtained from biopsies of skin lesions. The results are as follows:

\begin{tabular}{ccc} 
Case & $\begin{array}{c}\text { Percentage Fall in Biopsy Index } \\
\text { 1st } 6 \text { months }\end{array}$ & $\begin{array}{c}\text { 2nd } 6 \text { months } \\
1\end{array}$ \\
1 & 64 & 20 \\
2 & 27 & 41 \\
3 & 57 & 25 \\
4 & 55 & 50 \\
5 & 27 & 56 \\
\hline Mean & 46 & 28 \\
\hline
\end{tabular}

The corresponding figures for a series of 16 similar cases treated at the Jordan Hospital with sulphone alone are $33 \%$ for the first period of 6 months and $23 \%$ for the second; for another series of 28 lepromatous cases treated in overseas institutions but analysed by the same method, the corresponding figures are $30 \%$ and $22 \%$. The difference between the figures $46 \%$ for Vadrine plus sulphone and $33 \%$ or $30 \%$ for sulphone alone during the first 6 months accords with clinical impressions of the superior progress of the Vadrine cases during this period. In the second 6-monthly period the results are normally more erratic and the mean fall lower than in the first period because of the onset of ENL. Four out of 5 patients continued 
to make excellent bacteriological and histological progress during this second period even though two of them developed mild ENL. In the fifth patient (Case 3) ENL was sufficiently severe to necessitate interruption of treatment, and there was a bacteriological (though not a clinical) relapse. This has caused the mean fall in the index for the second period to be lowered to $28 \%$, which is only a little better than the expected figure for sulphone alone. It would probably have been justifiable to exclude this patient on account of the interruption of treatment, in which case the mean figure would have been $42 \%$ which is substantially better than the expected $22 \%$ or $23 \%$ for sulphone. However, in view of the individual variation in response, a larger series would have been needed to establish that the differences were statistically significant.

An interesting aspect of the figures is that one of these 5 patients, and one from the previous trial of Vadrine alone, showed two consecutive improvements of $50 \%$ or more for the first and second periods. This is an exceptional event which has never previously been observed at the Jordan Hospital.

\section{Conclusion}

The trial was too small to be conclusive, but the results suggest that the combination of Vadrine and sulphone is substantially superior to sulphone alone for the first stages of the treatment of lepromatous leprosy, or until the onset of ENL. As far as is known Vadrine has no toxic effects or contra-indications.

\section{Acknowledgments}

Our thanks are due to the Physicians at the Hospital for Tropical Diseases for their co-operation and permission to report on their patients; to Miss Marian Wise for preparing the histological sections, and to Edward Geistlich \& Sons, Ltd., Wolhusen, Switzerland, for generous supplies of Vadrine.

\section{Reference}

Jopling, W. H. and Ridley, D. S. (1958), Leprosy Review, 29, 143. 